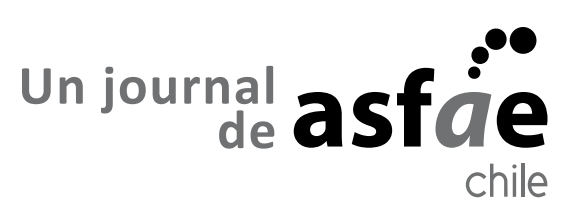

\title{
A STUDY ON THE IMPACT OF PERSONALITY TRAITS ON ATTITUDES TOWARDS SOCIAL MEDIA INFLUENCERS
}

\author{
UN ESTUDIO SOBRE EL IMPACTO DE LOS RASGOS DE PERSONALIDAD EN \\ LAS ACTITUDES HACIA LOS INFLUYENTES DE LAS REDES SOCIALES
}

\author{
Melisa Mete ${ }^{\mathrm{a}}$ \\ Classification: Empirical paper - research \\ Received: June 30, 2020 / Revised: September 25, 2020; November 29, 2020 / Accepted: February 9, 2021
}

\begin{abstract}
Companies increasingly collaborate with social media influencers (SMIs) to promote product and service brands (Jin \& Muqaddam, 2019). There has so far been limited research examining how the personality traits of consumers may impact the extent to which they are influenced by SMIs. This study aims to understand the relationship between consumers' personality traits and their attitudes towards SMIs. The study utilised an online questionnaire distributed to a group of millennials $(\mathrm{n}=221)$, in order to understand the impact of personality traits on attitudes towards SMIs. The five-factor model of personality (McCrae \& Costa, 1987), which employs the neuroticism, extraversion, openness, agreeableness, and conscientiousness labels, was used as a framework for the study, while the questions on attitudes towards SMIs explored four main areas - envy towards SMIs, advertising content value, credibility of SMIs, and perceived trustworthiness of SMIs. The findings highlight the importance of investigating personality traits to better understand how followers/consumers' perceptions and attitudes towards SMIs and SMI-endorsed advertisements can be influenced. The implications for further research and the study's limitations are discussed.
\end{abstract}

Keywords: social media influencers, influencer marketing, five factor model of personality, consumer attitudes towards influencers, millennials.

\section{Resumen}

Las empresas colaboran cada vez más con personas influyentes en las redes sociales (IRS) para promover marcas de productos y servicios (Jin y Muqaddam, 2019). Hasta ahora, se han realizado investigaciones limitadas que examinan cómo los rasgos de personalidad de los consumidores pueden afectar la medida en que están influenciados por las IRS. Este artículo tiene como objetivo comprender la relación entre los rasgos de personalidad de los consumidores y sus actitudes hacia los IRS. El estudio utilizó un cuestionario en línea distribuido a un grupo de millennials $(n=221)$, con el fin de comprender el efecto de los rasgos de personalidad en las actitudes hacia los IRS. El modelo de personalidad de cinco factores (McCrae y Costa, 1987), que emplean las etiquetas de neuroticismo, extraversión, apertura, amabilidad y conciencia, se utilizó como marco para el estudio, mientras que las preguntas sobre actitudes hacia los IRS exploraron cuatro áreas principales —envidia hacia los IRS, valor del contenido publicitario, credibilidad de los IRS y confianza percibida de los IRS. Los hallazgos destacan la importancia de investigar los rasgos de personalidad para comprender mejor cómo se pueden influir las percepciones y actitudes de los seguidores / consumidores hacia los IRS y los anuncios respaldados por IRS. Se discuten las implicaciones para futuras investigaciones y las limitaciones del estudio.

Palabras clave: influenciadores de redes sociales, marketing de influenciadores, modelo de personalidad de cinco factores, actitudes del consumidor hacia los influenciadores, millennials.

a Henley Business School, University of Reading, Reading, U.K. Email: m.mete@henley.ac.uk 


\section{Introduction}

Social media is considered an important part of daily life for a consumer. It has been estimated that in 2020, 3.81 billion people worldwide use at least one social media platform, with an average time of 144 minutes per day spent on social media (Statista, 2020). Consequently, social media platforms have changed how consumers share information about brands (Soltani-Nejad et al., 2020), and marketers realise that social media platforms can be used as powerful tools (Hooda \& Ankur, 2018). Thus, companies have started to work with social media influencers (SMIs) in order to promote their brands and products to consumers (Jin and Muqaddam, 2019; Schouten et al., 2020).

SMIs - ordinary people who have successfully built an online personal brand by enthusiastically sharing self-generated content (Lin et al., 2018; Schouten et al., 2020) - use their power to influence consumers' perceptions and decisions about brands (Wellman et al., 2020). They are usually perceived as experts in areas such as beauty, fitness or fashion, which increases their credibility (Khamis et al., 2017; Schouten et al., 2020). Studies have attempted to understand the mechanism by which influencer marketing affects consumers via social media, and recent research argues that there are several main aspects to be considered, including envy towards SMIs, the advertising content that brands want to communicate via SMIs, the credibility of the SMIs, and their perceived trustworthiness in the eyes of consumers (Chae, 2018; Lou \& Yuan, 2019).

Endorsers have a crucial role in marketing communications, through capturing attention, communicating meaning, providing information, and affecting consumer perceptions (De Veirman et al., 2017; Friedman \& Friedman, 1979; Ilicic \& Webster, 2011; McCracken, 1989; O’Mahony \& Meenaghan, 1997). There are several studies investigating how the personality of a celebrity or influencer should suit the product or service being endorsed, in order to create a successful marketing communication (Kamins, 1990; Kamins \& Gupta, 1994). Some focus on brand trait transference, which happens when endorsers acquire brand personality traits (Arsena et al., 2014), or vice versa (Ambroise et al., 2014). As personality traits can affect consumers' evaluations and perceptions (Azzadina et al., 2012), it is crucial to understand how an individual's personality affects their perceptions of endorsers. The present study addresses this under-researched area and provides empirical evidence for this relationship, through a focus on millennial consumers in the UK.

The millennial generation is defined as that including individuals born between 1985 and 1999 (Pendergast,
2010). Unlike their predecessors, who are identified as digital immigrants, most digital natives are millennials (Nella \& Christou, 2014; Prensky, 2001; Prensky, 2012). In fact, they are the first generation that has grown up entirely in the digital world, with their lives and work strongly affected by information technology (Bennett et al., 2008; Bolton et al., 2013; Wesner \& Miller, 2008). Bennett (2014) states that around three quarters of consumers make their purchasing decisions based on social media.

The millennial generation number around 1.8 billion individuals globally, which accounts for about a quarter of the world's population (Tinfold, 2018). They are one of the most active generations on social media (Chatzigeorgiou, 2017), and their number and combined purchasing power make millennials a very important market segment (Barnes, 2015).

\section{Personality Traits and Consumer Attitudes towards Brands endorsed by SMIs}

In order to better understand the perceptions and choices of consumers, and their attitudes towards brands in general, it is important to understand personality traits (Dolich, 1969; Mulyanegara et al., 2009). Research began to examine the relationship between personality traits and consumer behaviour, in order to explore how personality can affect consumers' buying behaviour (Foxall \& Goldsmith, 1988). Recent studies have focused on exploring means by which to measure personality (Singh et al., 2020), given the indication that personality traits are one of the main factors affecting decision making (Barkhi \& Wallace, 2007) and, consequently, consumer purchase intentions (Azzadina et al., 2012).

Although this study uses the five-factor model (McCrae \& Costa, 1987; Costa \& McCrae, 1992) to measure personality, there are several alternative approaches that exist in the literature in the context of brand and consumer relationships. For instance, in order to measure brand personality, Aaker (1997) designed a generic measurement scale that would enable the personalities of all types of brands to be measured, and after factor analysis was conducted, five dimensions emerged - sincerity, excitement, sophistication, ruggedness, and competence. However, this scale has been criticised on account of the fact that some of its dimensions cannot be replicated in certain cultures (Aaker et al., 2001; Davies et al., 2004; Muniz \& Marchetti, 2012; Sung \& Tinkham, 2005). It has also been criticised due to issues concerning generalisation, methodology, data collection and sampling (Austin et al., 2003). An alternative approach to Aaker's five dimensions, is the stereotype content model, which claims that people judge individuals or 
human groups in terms of their relative warmth and competence (Fiske et al., 2002). The warmth dimension concerns the perceived intentions of other people in terms of how friendly, helpful, and trustworthy they are, while competence concerns their perceived intentions when it comes to how competent, confident, and hardworking they are (Fiske et al., 2007). Davies et al. (2018) identify three dimensions (warmth, competence and status) to measure brand personality.

\section{Five-Factor Model}

Personality can be defined as traits of behaviour that establish the individual's pattern of interactions with their surroundings (McKenna, 2000). Personality research, which had been involved in debates and disparate theories (Funder, 2001), eventually led to a consensus that traits are well-structured within five broad, empirically driven domains (Ekinci \& Dawes, 2009). This was the five-factor model, also known as the Big Five or the five-factor theory, consisting of extroversion, agreeableness, conscientiousness, neuroticism, and openness (Costa \& McCrae,1992).

The five-factor model does not limit personality to only these five traits, but instead proposes that each trait summarises a greater set of characteristics (John \& Srivastava, 1999). Trait theory enables us to measure personality traits, which results in more effective quantitative research (Cervone \& Pervin, 2015). Numerous studies from different disciplines have been able to replicate the findings across observers, methodologies, life spans, and languages and cultures, thus validating this approach to measuring personality (Ekinci \& Dawes, 2009).

Based on the five-factor model, the five traits of personality are explained in the following parts in order to predict how this study expects the personalities of individuals to affect their attitudes towards SMIs.

\section{Extroversion}

Extroversion can be considered as the first dimension (Barrick \& Mount, 1991). People who score highly for extraversion are often stimulated by social interactions, and these individuals are usually talkative and energetic (McCrae \& John, 1992). Extroverts are natural leaders who are person-oriented, optimistic, fun-loving, affectionate and confident; extraversion is associated with strong positive feelings (Chamorro-Premuzic, 2016; Ekinci \& Dawes, 2009; McCrae \& Costa, 2003).

\section{Agreeableness}

Individuals who score highly for the agreeableness trait are trusting, helpful, generous, forgiving, courteous, coo- perative, and tolerant (McCrae \& Costa, 2003; Roccas et al., 2002). Agreeable people are generally kind, sympathetic and altruistic individuals (Digman, 1990; McCrae \& John, 1992). On the other hand, people with low agreeableness scores tend to be sceptical, spiteful, and hostile (Digman, 1990).

\section{Conscientiousness}

Conscientious individuals can be described as organised, dependable, responsible, punctual, and achievementoriented (Barrick \& Mount, 1991; Ekinci \& Dawes, 2009). Conscientious people are rational thinkers who prefer to be well-informed before making decisions (Chamorro-Premuzic, 2016). This trait is often described by using such terms as initiative, responsibility, and will power (Kluckholn et al., 1953; Costa et al., 1991). On the other hand, people with low conscientious scores are associated with thoughtless decisions (Roccas, et al., 2002).

\section{Neuroticism}

Individuals who score high for the neuroticism trait most often exhibit neurotic characteristics, such as worry, nervousness, and self-pity (Barrick \& Mount, 1991). Neurotic individuals are often temperamental and anxious (Briggs, 1988), and neuroticism is associated with low self-esteem (McCrae \& John, 1992). On the other hand, people with low neuroticism scores are usually calm, relaxed, self-assured, and emotionally stable (McCrae \& Costa, 2003).

\section{Openness}

Barrick and Mount (1991) state that openness has been the most challenging dimension to identify in personality research, and is interpreted mostly as describing people who are imaginative, creative, and open-minded. Individuals who score highly for openness are usually cultured, attentive to inner feelings, intellectual, curious, broadminded, intelligent, and sensitive to aesthetics (Ekinci \& Dawes, 2009). Those demonstrating this trait are likely to be inquisitive and to value knowledge. Conversely, individuals with low openness scores may value more conservative ideas (McCrae \& Costa, 2003).

\section{Social Media Influencers}

There is a dramatic rise in brands collaborating with SMIs to market their products and services (Jin \& Ryu, 2020), as companies realise that SMIs represent a new type of endorser who influences their followers' attitudes through the generated content on their social media 
platforms (Freberg et al., 2011). There are several reasons why marketers consider SMIs as important allies on their road to success; the most prominent one is that these endorsers have a wide reach and high numbers of followers (De Veirman et al., 2017). Also, unlike the more traditional digital marketing communication strategies, which lack engagement with potential consumers, collaborations with SMIs for brand advertising enable a company to reach consumers in a more genuine way (Childers et al., 2019). Although celebrity endorsement has been a very popular marketing strategy, nowadays brands increasingly prefer to collaborate with SMIs (Schouten et al., 2020). The justification for this preference can be derived from recent studies on how consumers' attitudes towards brands differ in terms of collaborations with SMIs or celebrity endorsers (Djafarova \& Rushworth, 2017).

This research focuses on four main attitudes towards SMIs: envy, advertising content evaluations, credibility, and trust.

\section{SMIs and Envy}

Envy is defined as 'the unpleasant emotion that can arise when we compare unfavourably with others' (Smith \& Kim, 2007, p. 46).

According to Smith (2004), there are four conditions for individuals to feel envious: envy arises when an individual and the envied target have similarities except for a desired attribute; the desired attribute is personally relevant for the individual, and the individual is not confident about his/her ability to obtain such an attribute and the envied target's advantage is seen as unfair (Chae, 2018). Envy occurs towards the people whom individuals identify with and who are characteristically closer to them. (Miceli \& Castelfranchi, 2007).

When compared with traditional celebrities, SMIs have more similarities with their followers: some of them are ordinary people who are still students, yet they might be considered more beautiful or wealthier than other ordinary people who aspire to be like them but find it difficult (Chae, 2018; Lou \& Yuan, 2019).

The study on envy and its relation to social media consumption is an emerging topic in marketing research (e.g., Appel et al., 2015; Chow \& Wan, 2017; Feng et al., 2021; Lee \& Eastin, 2020; Lin \& Utz, 2015; Liu \& Ma, 2018). A recent study that investigated the relationship between personality and envy towards SMIs concluded that females with low self-esteem and high self-consciousness are likely to feel envious towards SMIs (Chae, 2018).

A lot of academic research on personality concludes that individuals who are rated high on the neuroticism scale show a greater tendency to compare themselves with others, in turn, leading to negative feelings (Van der Zee et al., 1998).

Research by Wallace et al. (2017) showed a negative relationship between individuals who are rated high in terms of extraversion and their envy towards social media influencers. Hence:

H1: Individuals who score highly for neuroticism will show higher reported envy towards SMIs.

H2: Individuals who score highly for extraversion will show lower reported envy towards SMIs.

\section{SMIs and SMI Evaluation}

The value of third-party influencers for brands has been extensively researched, with a focus on the consumer influencer value (Kumar et al., 2010; Van den Bulte \& Wuyts, 2007). On the other hand, research on the value of SMIs is limited to only a few studies, but recent research from Lou and Yuan (2019) has resulted in the development of a social media influencer value (SMIV) model that discusses the effect of source credibility and the advertising value of SMIs. The main factors identified in the SMIV model are advertising content value, influencer credibility, perceived trust, brand awareness and purchase intentions. SMIs should consider these factors if they are to ensure positive attitudes from their followers, both towards themselves as individuals, and towards the brands they endorse (Lou \& Yuan, 2019).

\section{SMIs and Advertising Content Value}

Advertising content value can be determined by several factors, such as the importance of the information provided by the advertisements, and the form of the advertisements (Ducoffe, 1996). Similarly, research suggests that the success of a campaign depends on whether SMIs' posts are perceived as informative and entertaining (Dao et al., 2014; Lou \& Yuan, 2019). Research conducted with young female Instagram users to investigate the effects of celebrities and influencers concluded that influencers were more influential, credible, and relatable than traditional celebrities (Djafarova \& Rushworth, 2017). Lou and Yuan (2019) argue that the perceived informative and entertainment value of SMIs' content may affect followers' perceptions of specific branded posts, while Black et al. (2010) propose that participants who score more highly on the openness trait will have a positive attitude towards SMIs in advertising. Hence:

H3: Individuals who score highly for openness will show positive attitudes towards the use of SMIs in advertising. 


\section{SMIs and Credibility}

The credibility of a source or a communicator is one of the key determinants of persuasion (Hovland \& Weiss, 1951), and influencer credibility can therefore be similarly considered an important factor in influencing consumers (Lou \& Yuan, 2019).

Several studies investigate the credibility of SMIs as brand endorsers and conclude that consumers' perceptions of influencer credibility are an important determinant of successful marketing communications (Djafarova \&Rushworth, 2017; Schouten et al., 2020). There are four themes of influencer credibility that have emerged from recent studies on SMIs, namely the trustworthiness of SMIs, their authenticity, how knowledgeable they are, and their attractiveness (Lou \& Yuan, 2019; Schouten et al., 2020).

Previous studies on source credibility have explored the effect of endorsers on consumers (Dwivedi et al., 2015; Lee \& Koo, 2015). In the light of influencer marketing practices, Djafarova and Rushworth (2017) state that in order to be successful, SMI endorsers must be considered product-relevant by consumers. Similarly, Schouten et al. (2020) contend that when SMIs are perceived as credible and useful, they have a positive effect on individuals' perceptions of the brands they endorse, and on their purchase intentions (Chapple \& Cownie, 2017; Miranda et al., 2019).

Considering the main attributes of conscientiousness, such as rational thinking and being well-informed before making decisions:

H4: Individuals who score highly for conscientiousness will show higher perceived credibility towards SMIs.

\section{SMIs and Trust}

Trust can be described as 'a willingness to rely on an exchange partner in whom one has confidence' (Moorman et al., 1993, p. 82). The importance of trust in the context of social media marketing has been a popular research area (studies include Chu \& Kim, 2011; Hajli, 2014; Yahia et al., 2018).

In the context of SMIs, if followers are to consider purchasing the brands that SMIs endorse, they must perceive the SMIs as trustworthy (Wellman et al., 2020), and as reliable sources of information (Schouten et al., 2020). Lou and Yuan (2019) propose an integrated social media influencer value model that considers the perceived trustworthiness of SMIs as a significant aspect. Of the five personality factors, agreeableness, which captures one's tendency toward cooperation and concern for social relationships (Levine et al., 2018), is the only one that always shows a positive relationship with trust (Ben-Ner \& Halldorsson, 2010; Evans \& Revelle, 2008). Furthermore, agreeable individuals are rarely considered suspicious of hidden intentions (McCrae \& Costa, 2003). Therefore:

H5: Individuals who score highly for agreeableness will perceive SMIs to be more trustworthy.

The conceptual framework and the proposed hypotheses of this research are presented in Figure 1, below.

Figure1. Conceptual Framework with Hypotheses

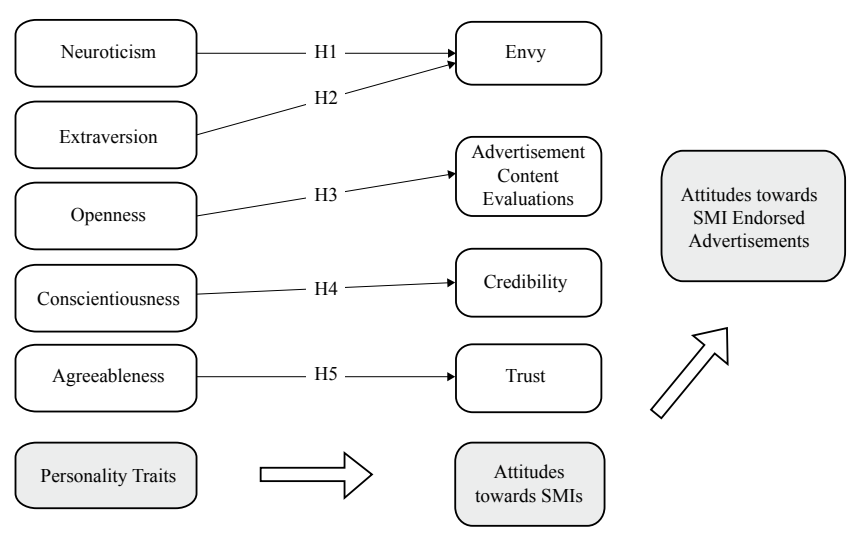

\section{Method}

\section{Sample}

The participant sample consists of millennials (born between 1985 and 1999) residing in the UK. Participation was voluntary, and an online questionnaire was embedded on an online survey tool and distributed. After removing any participants who failed the filtering and screening questions, the final number of participants included in data analysis was 221 .

The average age of participants was 29 , with $52 \%$ being male and $48 \%$ female.

As shown in Table 1, almost $93 \%$ of the participants had Facebook accounts (although only $46 \%$ were actively using their accounts), $62 \%$ had YouTube accounts, and $92 \%$ had accounts on Instagram (reported active usage was $72 \%)$.

Over half of the participants responded that they follow influencers on YouTube (53\%), 34\% follow influencers on Facebook, and 81\% follow Instagram influencers.

\section{Procedure}

First, the participants were asked two screening questions about their social media use and influencer following habits. Lou and Yuan (2019) defined SMIs as regular 
Table 1. Demographics of the Respondents

\begin{tabular}{|c|c|c|c|}
\hline Demographics & Classification & Frequency & Percentage $\%$ \\
\hline \multirow{2}{*}{ Gender } & Male & 116 & 52 \\
\hline & Female & 106 & 48 \\
\hline \multirow{3}{*}{ Age } & $20-24$ & 65 & 29 \\
\hline & $25-29$ & 79 & 36 \\
\hline & $30-35$ & 77 & 35 \\
\hline \multirow{4}{*}{ Occupation } & Student & 115 & 52 \\
\hline & Employed & 93 & 42 \\
\hline & Self-Employed & 9 & 4 \\
\hline & Prefer not to answer & 4 & 2 \\
\hline \multirow{6}{*}{$\begin{array}{l}\text { Respondents } \\
\text { who have an } \\
\text { account on... }\end{array}$} & Facebook & 206 & 93 \\
\hline & Instagram & 203 & 92 \\
\hline & YouTube & 137 & 62 \\
\hline & Twitter & 152 & 69 \\
\hline & TikTok & 52 & 24 \\
\hline & Others & 42 & 19 \\
\hline \multirow{6}{*}{$\begin{array}{l}\text { Respondents } \\
\text { who are active } \\
\text { users of... }\end{array}$} & Facebook & 95 & 46 \\
\hline & Instagram & 146 & 72 \\
\hline & YouTube & 84 & 61 \\
\hline & Twitter & 102 & 67 \\
\hline & TikTok & 40 & 77 \\
\hline & Others & 37 & 88 \\
\hline
\end{tabular}

people who have become online celebrities with a large number of followers by creating and posting content across one or more social media platforms (such as YouTube, Instagram, Snapchat, or personal blogs), and this definition was given to the respondents to ensure a uniform and consistent understanding of the concept of SMIs. Participants who were regular social media users (actively using at least one social media platform) and had followed at least one influencer within the last year were directed to fill in the main survey questions. They were asked about their experiences and habits regarding their social media use, their thoughts and perceptions about the social media influencers whom they had followed, and their demographic information. The survey took around 10 minutes to complete.

\section{Measures}

The big five inventory (BFI) was used to measure the 5 dimensions of personality $(1=$ strongly disagree to 7 = strongly agree; all $\alpha$ are above .85) (John $\&$ Sirivastava, 1999).

This study measured the four main areas that affect consumers' perceptions of SMIs with all items extracted from Chae (2018), Lou and Yuan (2019), Munnukka et al. (2016), and Ohanian (1990), as well as consum- ers' general attitudes towards SMI-endorsed advertisements with all items extracted from Tan \& Chia (2007). The responses were anchored by a 7-point Likert scale.

Envy

Participants' envy towards SMIs was measured with a three-item construct taken directly from Chae (2018), which had been adapted from Appel et al. (2015): 'I envy the influencers' lives shown on social media', 'My life is inferior to influencers' lives shown on social media' and 'I wish to live like influencers on social media'. The items were based on a 7 -point scale $(1=$ strongly disagree to $7=$ strongly agree).

\section{Advertising content evaluation}

Participants' perceptions towards advertisement content value were measured with a three-item construct, with two items adapted from Munnukka et al. (2016): 'Use of SMIs in advertising brands is enjoyable' and 'Use of SMIs in advertising brands is interesting', and another item was adapted from Lou and Yuan (2019): 'Advertisements from SMIs are informative'. The items were based on a 7-point scale $(1=$ strongly disagree to $7=$ strongly agree $)$.

\section{Credibility}

Participants perceptions towards SMIs credibility were measured with a three-item construct with one item adapted from Munnukka et al. (2016): 'I consider the SMIs very attractive' and two items adapted from Lou and Yuan (2019): 'I consider the SMIs authentic and credible' and 'I consider the SMIs very knowledgeable about their endorsed brands'. The items were based on a 7-point scale $(1=$ strongly disagree to $7=$ strongly agree $)$.

\section{Trust}

Participants perceptions towards SMIs trustworthiness were measured with a four-item construct adapted from Munnukka et al. (2016): 'I feel SMIs are honest', 'I consider SMIs are trustworthy', 'I feel SMIs are truthful', and 'I consider SMIs are earnest'. The items were based on a 7 -point scale $(1=$ strongly disagree to $7=$ strongly agree).

\section{Attitudes towards SMI-endorsed advertisements}

Participants' general attitudes towards SMI-endorsed advertisements were measured with a three-item construct adapted from Tan and Chia (2007): 'Overall, I consider SMI-endorsed advertising a good thing', 'Overall, I like SMI-endorsed advertising', and 'My general opinion of SMI-endorsed advertising is unfavourable' (reverse scored). The items were based on a 7-point scale $(1=$ strongly disagree to $7=$ strongly agree $)$. 


\section{Findings}

The mean values for each dimension of personality were calculated: neuroticism $(\mathrm{M}=5.23)$, extraversion $(\mathrm{M}=5.81)$, openness $(\mathrm{M}=5.72)$, agreeableness $(\mathrm{M}=5.51)$, and conscientiousness $(\mathrm{M}=5.13)$.

Then, the internal consistencies of Envy ( $\alpha=.89$ ), Advertising content evaluation $(\alpha=.89)$, Credibility ( $\alpha=.91)$, Trust $(\alpha=.91)$, and Attitudes towards SMI endorsed advertisements $(\alpha=.86)$ were calculated. All of the Cronbach Alpha values were reported as high (Nunnally, 1978; Peterson, 1994).

After the internal consistencies were checked, T-tests were carried out in order to understand whether there is a significant difference in the perceived attitudes towards SMIs due to reported scores of the personality traits being high or low.

\section{Envy}

The study found that participants who scored highly for neuroticism had significantly higher reported envy towards SMIs $(6.09 \pm 1.16)$, compared to those participants who showed low neuroticism scores $(5.35 \pm 1.01)$, $\mathrm{t}(219)=4.50, \mathrm{p}=.02$, supporting $\mathrm{H} 1$.

The participants who scored highly for extraversion had slightly higher reported envy towards SMIs (6.02 \pm 0.83 ), compared to the participants who showed low extraversion scores $(5.98 \pm .95), \mathrm{t}(219)=1.02$. However, the mean differences are not statistically significant, with $\mathrm{p}=.35$, and therefore $\mathrm{H} 2$ is not supported.

\section{Advertising Content Evaluation}

Participants with high openness scores showed significantly higher positive attitudes towards the use of SMIs in advertising $(6.10 \pm 1.02)$, compared to participants with low scores for openness $(5.28 \pm 1.30), t(219)=5.14$, $\mathrm{p}=.001$, supporting H3.

\section{Credibility}

The analyses showed that participants who scored highly for conscientiousness showed significantly higher perceived credibility towards SMIs $(6.58 \pm 0.54)$, compared to the participants with low scores for conscientiousness $(5.58 \pm 1.23), \mathrm{t}(219)=5.71, \mathrm{p}=.001$, supporting $\mathrm{H} 4$.

\section{Trust}

The study found that participants who scored highly for agreeableness had significantly higher reported trust towards SMIs $(6.07 \pm 1.10)$, compared to the participants with low scores for agreeableness $(5.40 \pm 1.19)$, $\mathrm{t}(219)=4.24, \mathrm{p}=.012$, supporting H5.
After the mean comparisons, possible moderation effects of different personality traits were investigated. In order to understand whether personality traits moderate the relationship between four main attitudes towards SMIs and attitudes towards SMI-endorsed advertisements, the Process Macro was used (Hayes, 2012). Process Model 1 was tested for possible moderation effects of different personality traits from different attitudes towards SMIs to consumers' attitudes towards SMI-endorsed advertisements (Figure 2).

Figure 2. Process Model 1 for Direct Moderation of Different Personality Traits
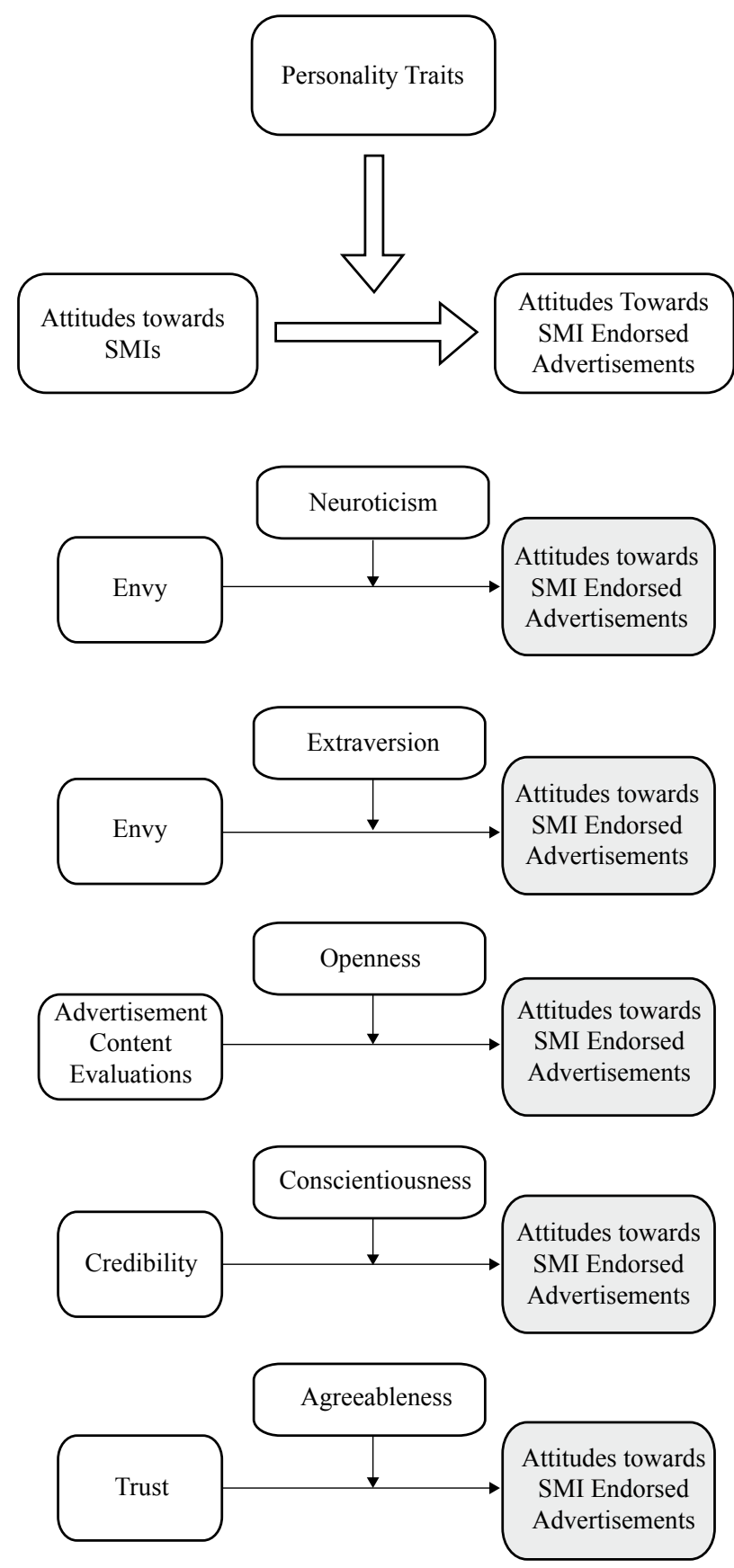
First the relationship between envy towards SMIs and attitudes towards SMI-endorsed advertisements was tested with neuroticism as a moderator, $(\mathrm{n}=221), \mathrm{P}=.63$ for interaction, $\mathrm{P}=.0005$ for neuroticism. Although the model was significant $(\mathrm{P}=.000)$, moderation was not significant.

The same test was conducted with extraversion as the moderator; and the results showed that the moderation was not significant with $\mathrm{P}=.29$ for interaction, and $\mathrm{P}=.24$ for extraversion.

The relationship between advertisement content evaluations for SMIs and attitudes towards SMI-endorsed advertisements was tested with openness as a moderator, and the results were that moderation was not significant, with $\mathrm{P}=.52$ for interaction, and $\mathrm{P}=.95$ for openness.

The relationship between the credibility of SMIs and attitudes towards SMI-endorsed advertisements was tested with conscientiousness as a moderator $(\mathrm{P}=.045$ for interaction, $\mathrm{P}=.00$ for conscientiousness). It can be concluded that there is a statistically significant relationship between the credibility of SMIs and attitudes towards SMI-endorsed advertisements, and that this relationship is moderated by the conscientiousness trait.

Finally, the relationship between trust in SMIs and attitudes towards SMI-endorsed advertisements was tested with agreeableness as a moderator $(\mathrm{P}=.001$ for interaction, $\mathrm{P}=.005$ for agreeableness). This indicates a statistically significant relationship between trust in SMIs and attitudes towards SMI-endorsed advertisements. The agreeableness trait moderates this relationship.

\section{Discussion and Implications}

The role of personality traits in the current study mostly confirmed and, in some cases, extended the findings of previous studies. While previous research has addressed how personality affects preferences towards brands, little effort has been devoted to understanding the significance of individual personality traits in affecting perceptions and attitudes towards SMIs. This is the first research to investigate how the individual personality traits of British millennial followers, attitudes towards SMIs, and attitudes towards SMI-endorsed advertisements are related in social media marketing research. The findings can help marketers to gain a better understanding of how different personality traits can influence the attitudes and perceptions of potential consumers when it comes to the social media influencers they follow.

This study supports previous research concerning consumers' envy towards brand endorsers, particularly SMIs (Chae, 2018), and links the relationship between envy and comparing oneself with others and feeling negative emotions from these comparisons, with the neuroticism trait of personality (Van der Zee et al., 1998).

The first conclusion (H1) relating to the neuroticism personality trait and its relationship with envy towards SMIs is supported. This conclusion contributes to the theory on neuroticism and how its relationship towards feeling envious of SMIs would affect the purchase intentions of consumers who rate highly for neuroticism. The implication of this relationship for marketers is important, as there are numerous studies showing how envy towards SMIs affects attitudes towards SMI-endorsed advertisements and purchase intentions of consumers (Lin, 2018). Marketers can benefit from the finding that consumers who score highly for neuroticism also report higher envy towards SMIs, indicating that their purchase intentions would be lower compared to consumers with low neuroticism scores.

On the other hand, contrary to previous research (Wallace et al., 2017), the negative relationship between individuals who rated highly for extraversion and their envy towards social media influencers is not supported in this study (H2). One explanation might be that the majority of participants in reference studies were between 18 and 22 (for example Wallace et al., 2017), whereas this study has an older sample with an average age of 29. It may be that extraverted millennials might not feel as envious as younger generations in their perceptions of SMIs. Therefore, marketers need not view potential envy towards SMIs as a reason to exclude extravert millennials from their target demographic. With that said, they may want to consider how these factors interact in different age groups, as this may affect their purchase intentions.

In the context of advertisements involving SMIs, this study supports the previous research in terms of how the perceived informative and entertainment value of SMIs' content affects the followers' perceptions of endorsed brands (Lou \& Yuan, 2019), particularly with followers who report higher openness (H3).

Additionally, this study reflects the findings of previous research showing that consumers' perceptions of influencer credibility are an important determinant of successful marketing communications (Schouten et al., 2020), and adds that conscientiousness is an important personality trait for followers, one that has a positive relationship with perceived influencer credibility and should be included in future research when investigating this relationship further $(\mathrm{H} 4)$.

Similarly, marketers need to ensure the SMIs they collaborate with are perceived as trustworthy if followers are to increase their potential to purchase the endorsed brands (Wellman et al., 2020). This study contributes to this area by specifically suggesting that the agreeableness 
trait has a significant effect on the perceptions of SMIs' trustworthiness.

In terms of implications for practitioners, the most important conclusion is that marketers need to strategically consider how the four areas that influence consumers' perceptions of SMIs are affected by the different personality traits of their potential consumers.

Consumers who have more trust in SMIs indicated more positive attitudes towards SMI-endorsed advertisements. These interaction effects suggest that product/ brand placement strategies can benefit from differentiation that takes into account the moderating effects of followers' personalities (more agreeable vs less agreeable). These findings provide useful insights for marketers when it comes to communicating their brands with the help of campaigns leveraging influencers.

The main implication for influencers is that it is important to understand how followers with different personalities differ in their perceptions and attitudes towards SMIs and the brands that they endorse. For instance, their perceived credibility positively affects the followers' attitudes towards the brands, and this link is stronger for followers who score more highly for the conscientiousness trait.

It is also important to note that there is no statistically significant difference between genders when investigating the above relationships. Although past studies mainly focused on female consumers (e.g. Chae, 2018; Djafarova \& Rushworth, 2017), this study contributes to the literature by providing a broader perspective with the inclusion of all genders.

\section{Limitations and Suggestions for Future Research}

There are several limitations to this research. Firstly, the participants of the study were limited to UK residents within a specific age range. Secondly, the data were collected by means of online questionnaires with volunteers as respondents, which leads to the limitation of the use of non-probability sampling. Accordingly, future research should consider using a more comprehensive sampling design.

Given that the age range of respondents in this study was, as mentioned, limited, it would be interesting to investigate how their perceptions and attitudes might change over time. Future research could also consider different age groups or generations.

Finally, additional studies with respondents from different countries and cultures are needed, in order to facilitate greater generalisability of results.

\section{References}

Aaker, J. L. (1997). Dimensions of brand personality. Journal of Marketing Research, 34(3), 347-356.

Aaker, J. L., Benet-Martinez, V., \& Garolera, J. (2001). Consumption symbols as carriers of culture: A study of Japanese and Spanish brand personality constructs. Journal of Personality and Social Psychology, 81(3), 492.

Austin, J. R., Siguaw, J. A., \& Mattila, A. S. (2003). A re-examination of the generalizability of the Aaker brand personality measurement framework. Journal of Strategic Marketing, 11(2), 77-92.

Ambroise, L., Pantin-Sohier, G., Valette-Florence, P., \& Albert, N. (2014). From endorsement to celebrity co-branding: Personality transfer. Journal of Brand Management, 21(4), 273-285.

Appel, H., Crusius, J., \& Gerlach, A. L. (2015). Social comparison, envy, and depression on Facebook: A study looking at the effects of high comparison standards on depressed individuals. Journal of Social and Clinical Psychology, 34(4), 277-289.

Arsena, A., Silvera, D. H., \& Pandelaere, M. (2014). Brand trait transference: When celebrity endorsers acquire brand personality traits. Journal of Business Research, 67(7), 1537-1543.

Azzadina, I., Huda, A. N., \& Sianipar, C. P. M. (2012). Understanding relationship between personality types, Marketing-mix factors, and purchasing decisions. Procedia-Social and Behavioural Sciences, 65 , 352-357.

Barnes, N. G. (2015). EWOM drives social commerce: A survey of millennials in US and abroad. Journal of Marketing Development and Competitiveness, 9(2), 36.

Barkhi, R., \& Wallace, L. (2007). The impact of personality type on purchasing decisions in virtual stores. Information Technology and Management, 8(4), 313-330.

Barrick, M. R., \& Mount, M. K. (1991). The big five personality dimensions and job performance: A meta-analysis. Personnel Psychology, 44(1), 1-26.

Ben-Ner, A., \& Halldorsson, F. (2010). Trusting and trustworthiness: What are they, how to measure them, and what affects them. Journal of Economic Psychology, 31(1), 64-79.

Bennett, S. (2014, April 25). Social media business statistics, facts, figures \& trends 2014. Adweek. http://www.adweek.com/socialtimes/social-business-trends2014/498129

Bennett, S., Maton, K., \& Kervin, L. (2008). The 'digital natives' debate: A critical review of the evidence. British Journal of Educational Technology, 39(5), 775-786. 
Black, I. R., Organ, G. C., \& Morton, P. (2010). The effect of personality on response to sexual appeals. European Journal of Marketing, 44(9/10), 1453.

Bolton, R.N., Parasuraman, A., Hoefnagels, A.H.J.M., Migchels, N.G., Kabadayi, S., Gruber, T., Komarova Loureiro, Y. \& Solnet, D. (2013). Understanding Generation $Y$ and their use of social media: A review and research agenda. Journal of Service Management, 24(3), 245-267.

Briggs, S. R. (1988). Shyness: Introversion or neuroticism? Journal of Research in Personality, 22(3), 290-307.

Cervone, D., \& Pervin, L. A. (2015). Personality: Theory and research. John Wiley \& Sons.

Chae, J. (2018). Explaining females' envy toward social media influencers. Media Psychology, 21(2), 246-262.

Chamorro-Premuzic, T. (2016). Personality and individual differences. John Wiley \& Sons.

Chapple, C., \& Cownie, F. (2017). An investigation into viewers' trust in and response towards disclosed paid-for-endorsements by YouTube lifestyle vloggers. Journal of Promotional Communications, 5(2), 110-136.

Chatzigeorgiou, C. (2017). Modelling the impact of social media influencers on behavioural intentions of millennials: The case of tourism in rural areas in Greece. Journal of Tourism, Heritage \& Services Marketing, 3(2), 25-29.

Childers, C. C., Lemon, L. L., \& Hoy, M. G. (2019). \#Sponsored \#Ad: Agency perspective on influencer marketing campaigns. Journal of Current Issues \& Research in Advertising, 40(3), 258-274.

Chow, T. S., \& Wan, H. Y. (2017). Is there any 'Facebook Depression'? Exploring the moderating roles of neuroticism, Facebook social comparison and envy. Personality and Individual Differences, 119, 277-282.

Chu, S. C., \& Kim, Y. (2011). Determinants of consumer engagement in electronic word-of-mouth (eWOM) in social networking sites. International Journal of $A d-$ vertising, 30(1), 47-75.

Costa, P. T., Jr \& McCrae, R. R. (1992). Revised NEO Personality Inventory (NEO-PI-R) and NEO Five-Factor Inventory (NEO-FFI) professional manual. Odessa, FL: Psychological Assessment Resources.

Costa Jr, P. T., McCrae, R. R., \& Dye, D. A. (1991). Facet scales for agreeableness and conscientiousness: A revision of the NEO Personality Inventory. Personality and Individual Differences, 12(9), 887-898.

Dao, W. V. T., Le, A. N. N., \& Cheng, J. M. S. (2014). Social media advertising value: The case of transitional economies in Southeast Asia. International Journal of Advertising, 33(2), 271-294.
Davies, G., Chun, R., da Silva, R. V., \& Roper, S. (2004). A corporate character scale to assess employee and customer views of organization reputation. Corporate Reputation Review, 7(2), 125-146.

Davies, G., Rojas-Méndez, J. I., Whelan, S., Mete, M., \& Loo, T. (2018). Brand personality: Theory and dimensionality. Journal of Product \& Brand Management, 27(2), 115-127.

De Veirman, M., Cauberghe, V., \& Hudders, L. (2017). Marketing through Instagram influencers: The impact of number of followers and product divergence on brand attitude. International Journal of Advertising, 36(5), 798-828.

Digman, J. M. (1990). Personality structure: Emergence of the five-factor model. Annual Review of Psychology, 4l(1), 417-440.

Djafarova, E., \& Rushworth, C. (2017). Exploring the credibility of online celebrities' Instagram profiles in influencing the purchase decisions of young female users. Computers in Human Behaviour, 68, 1-7.

Ducoffe, R. H. (1996). Advertising value and advertising on the web-Blog@ management. Journal of Advertising Research, 36(5), 21-32.

Dolich, I. J. (1969). Congruence relationships between self-images and product brands. Journal of Marketing Research, 6(1), 80-84.

Dwivedi, A., Johnson, L. W., \& McDonald, R. E. (2015). Celebrity endorsement, self-brand connection and consumer-based brand equity. Journal of Product and Brand Management, 24(5), 449-461.

Ekinci, Y., \& Dawes, P. L. (2009). Consumer perceptions of frontline service employee personality traits, interaction quality, and consumer satisfaction. The Service Industries Journal, 29(4), 503-521.

Evans, A. M., \& Revelle, W. (2008). Survey and behavioural measurements of interpersonal trust. Journal of Research in Personality, 42(6), 1585-1593.

Feng, W., Yang, M. X., Yu, I. Y., \& Tu, R. (2021). When positive reviews on social networking sites backfire: The role of social comparison and malicious envy. Journal of Hospitality Marketing \& Management, 30(1), 120-138..

Fiske, S. T., Cuddy, A. J., \& Glick, P. (2007). Universal dimensions of social cognition: Warmth and competence. Trends in Cognitive Sciences, 11(2), 77-83.

Fiske, S. T., Cuddy, A. J., Glick, P., \& Xu, J. (2002). A model of (often mixed) stereotype content: competence and warmth respectively follow from perceived status and competition. Journal of Personality and Social Psychology, 82(6), 878-902. 
Foxall, G. R., \& Goldsmith, R. E. (1988). Personality and consumer research: Another look. Journal of the Market Research Society, 30(2), 111-125.

Freberg, K., Graham, K., McGaughey, K., \& Freberg, L. A. (2011). Who are the social media influencers? A study of public perceptions of personality. Public Relations Review, 37(1), 90-92.

Friedman, H. H., \& Friedman, L. (1979). Endorser effectiveness by product type. Journal of Advertising Research, 19, 63-71.

Funder, D.C. (2001). Personality. Annual Review of Psychology, 52(1), 197-221.

Hajli, M. N. (2014). A study of the impact of social media on consumers. International Journal of Market Research, 56(3), 387-404.

Hayes, A. F. (2012). PROCESS: A versatile computational tool for observed variable mediation, moderation, and conditional process modelling [White paper]. http://www.afhayes.com/public/process2012.pdf

Hooda, A., \& Ankur, A. (2018). Acceptance of social media as a marketing tool: A quantitative study. The Journal of Business Economics and Environmental Studies, 8(3), 5-12.

Hovland, C. I., \& Weiss, W. (1951). The influence of source credibility on communication effectiveness. Public Opinion Quarterly, 15(4), 635-650.

Ilicic, J., \& Webster, C. M. (2011). Effects of multiple endorsements and consumer-celebrity attachment on attitude and purchase intention. Australasian Marketing Journal (AMJ), 19(4), 230-237.

Jin, S. V., \& Muqaddam, A. (2019). Product placement 2.0: "Do brands need influencers, or do influencers need brands?". Journal of Brand Management, 26(5), 522-537.

Jin, S. V., \& Ryu, E. (2020). "I'll buy what she's \#wearing": The roles of envy toward and parasocial interaction with influencers in Instagram celebrity-based brand endorsement and social commerce. Journal of Retailing and Consumer Services, 55, 102-121.

John, O.P., \& Srivastava, S. (1999). The big-five trait taxonomy: History, measurement, and theoretical perspectives. In L.A. Pervin \& O.P. John (Eds.), Handbook of personality: Theory and research (pp. 102-138). Guildford Press.

Kamins, M. A. (1990). An investigation into the "matchup" hypothesis in celebrity advertising: When beauty may be only skin deep. Journal of Advertising, 19(1), 4-13.

Kamins, M. A., \& Gupta, K. (1994). Congruence between spokesperson and product type: A matchup hypothesis perspective. Psychology \& Marketing, 11(6), 569-586.
Khamis, S., Ang, L., \& Welling, R. (2017). Self-branding, 'micro-celebrity' and the rise of Social Media Influencers. Celebrity Studies, 8(2), 191-208.

Kluckhohn, C., Murray, H. A., \& Schneider, D. M. (1953). Personality in nature, society, and culture (2nd ed.). Knopf.

Kumar, V., Aksoy, L., Donkers, B., Venkatesan, R., Wiesel, T., \& Tillmanns, S. (2010). Undervalued or overvalued customers: Capturing total customer engagement value. Journal of Service Research, 13(3), 297-310

Lee, J. A., \& Eastin, M. S. (2020). I like what she's \#endorsing: The impact of female social media influencers' perceived sincerity, consumer envy, and product type. Journal of Interactive Advertising, 20(1), 76-91.

Lee, Y., \& Koo, J. (2015). Athlete endorsement, attitudes, and purchase intention: The interaction effect between athlete endorser-product congruence and endorser credibility. Journal of Sport Management, 29(5), 523-538.

Levine, E. E., Bitterly, T. B., Cohen, T. R., \& Schweitzer, M. E. (2018). Who is trustworthy? Predicting trustworthy intentions and behaviour. Journal of Personality and Social Psychology, 115(3), 468.

Lin, R. (2018). Silver lining of envy on social media? The relationships between post content, envy type, and purchase intentions. Internet Research, 28(4), 1142-1164.

Lin, H. C., Bruning, P. F., \& Swarna, H. (2018). Using online opinion leaders to promote the hedonic and utilitarian value of products and services. Business Horizons, 61(3), 431-442.

Lin, R., \& Utz, S. (2015). The emotional responses of browsing Facebook: Happiness, envy, and the role of tie strength. Computers in Human Behaviour, 52, 29-38.

Liu, C., \& Ma, J. (2018). Social media addiction and burnout: The mediating roles of envy and social media use anxiety. Current Psychology, 39, 1883-1891.

Lou, C., \& Yuan, S. (2019). Influencer marketing: How message value and credibility affect consumer trust of branded content on social media. Journal of Interactive Advertising, 19(1), 58-73.

McCracken, G. (1989). Who is the celebrity endorser? Cultural foundations of the endorsement process. Journal of Consumer Research, 16(3), 310-321.

McCrae, R. R., \& Costa, P. T. (1987). Validation of the five-factor model of personality across instruments and observers. Journal of Personality and Social Psychology, 52(1), 81-90.

McCrae, R. R., \& Costa, P. T. (2003). Personality in adulthood: A five-factor theory perspective. Guilford Press. 
McCrae, R.R. \& John, O.P. (1992). An introduction to the five-factor model and its applications. Journal of Personality, 60(2), pp.175-215.

McKenna, E.F. (2000). Business psychology and organisational behaviour: A student's handbook (3rd ed.). England: Psychology Press.

Miceli, M., \& Castelfranchi, C. (2007). The envious mind. Cognition and Emotion, 21(3), 449-479.

Miranda, S., Cunha, P., \& Duarte, M. (2019). An integrated model of factors affecting consumer attitudes and intentions towards youtuber-generated product content. Review of Managerial Science, 15, 55-73.

Moorman, C., Deshpande, R., \& Zaltman, G. (1993). Factors affecting trust in market research relationships. Journal of Marketing, 57(1), 81-101.

Mulyanegara, R. C., Tsarenko, Y., \& Anderson, A. (2009). The big five and brand personality: Investigating the impact of consumer personality on preferences towards particular brand personality. Journal of Brand Management, 16(4), 234-247.

Muniz, K. M., \& Marchetti, R. Z. (2012). Brand personality dimensions in the Brazilian context. BAR-Brazilian Administration Review, 9(2), 168-188.

Munnukka, J., Uusitalo, O., \& Toivonen, H. (2016). Credibility of a peer endorser and advertising effectiveness. Journal of Consumer Marketing. 3(3), 182-192.

Nella, A., \& Christou, E. (2014). Linking service quality at the cellar door with brand equity building. Journal of Hospitality Marketing \& Management, 23(7), 699-721.

Nunnally, J. C. (1978). Psychometric theory (2nd ed.). Mcgraw-Hill.

Ohanian, R. (1990). Construction and validation of a scale to measure celebrity endorsers' perceived expertise, trustworthiness, and attractiveness. Journal of Advertising, 19(3), 39-52.

O'Mahony, S., \& Meenaghan, T. (1997). The impact of celebrity endorsements on consumers. Irish Marketing Review, 10(2), 15.

Pendergast, D. (2010). Getting to know the Y generation. Tourism and Generation Y, 1, 1-15.

Peterson, R. A. (1994). A meta-analysis of Cronbach's coefficient alpha. Journal of Consumer Research, 21(2), 381-391.

Prensky, M. (2001). Digital natives, digital immigrants. On the Horizon, 9(5), 1-6.

Prensky, M. R. (2012). From digital natives to digital wisdom: Hopeful essays for 21 st century learning. Corwin Press.

Roccas, S., Sagiv, L., Schwartz, S. H., \& Knafo, A. (2002). The big five personality factors and personal values. Personality and Social Psychology Bulletin, 28(6), 789-801.
Schouten, A. P., Janssen, L., \& Verspaget, M. (2020). Celebrity vs. Influencer endorsements in advertising: The role of identification, credibility, and product-endorser fit. International Journal of Advertising, 39(2), 258-281.

Singh, D., Bajpai, N., \& Kulshreshtha, K. (2020). Brand experience-brand love relationship for Indian hypermarket brands: The moderating role of customer personality traits. Journal of Relationship Marketing, 20(1), 20-41.

Smith, R. H. (2004). Envy and its transmutations. In L. Z. Tiedens \& C. W. Leach (Eds.), The social life of emotions (pp. 43- 63). Cambridge University Press.

Smith, R. H., \& Kim, S. H. (2007). Comprehending envy. Psychological Bulletin, 133(1), 46-64.

Soltani-Nejad, N., Mirezati, S. Z., \& Saberi, M. K. (2020). Predicting intention to share information on commercial websites based on personality traits. The Bottom Line, 33(3), 251-261.

Statista (2020). Social Media Statistics and Facts. https:// www.statista.com/topics/1164/social-networks/

Tinfold, C. (2018, June 6). The millennial moment- in charts. The New York Times. https://www.ft.com/ content/f81ac17a-68ae-11e8-b6eb-4acfcfb08c11

Sung, Y., \& Tinkham, S. F. (2005). Brand personality structures in the United States and Korea: Common and culture-specific factors. Journal of Consumer Psychology, 15(4), 334-350.

Tan, S. J., \& Chia, L. (2007). Are we measuring the same attitude? Understanding media effects on attitude towards advertising. Marketing Theory, 7(4), 353-377.

Van den Bulte, C. \& Wuyts, S. (2007). Social networks and marketing. Marketing Science Institute.

Van der Zee, K., Buunk, B. \& Sanderman, R., 1998. Neuroticism and reactions to social comparison information among cancer patients. Journal of Personality, 66(2), pp.175-194.

Wallace, L., James, T. L., \& Warkentin, M. (2017). How do you feel about your friends? Understanding situational envy in online social networks. Information \& Management, 54(5), 669-682.

Wellman, M. L., Stoldt, R., Tully, M., \& Ekdale, B. (2020). Ethics of authenticity: Social media influencers and the production of sponsored content. Journal of Media Ethics, 35(2), 68-82.

Wesner, M. S., \& Miller, T. (2008). Boomers and millennials have much in common. Organization Development Journal, 26(3), 89.

Yahia, I. B., Al-Neama, N., \& Kerbache, L. (2018). Investigating the drivers for social commerce in social media platforms: Importance of trust, social support and the platform perceived usage. Journal of Retailing and Consumer Services, 41, 11-19. 